\author{
European Dana Alliance \\ for the Brain
}

\section{International Brain Awareness Week: 14-20 March 2005}

\section{What weighs less than $1.5 \mathrm{~kg}$, and runs on the same amount of electrical power as a night light?}

The human brain - which has the most complex structure yet discovered. But scientists learn more about how it works every day.

Brain Awareness Week, taking place every March, is a global celebration of the latest brain science. It is organised by the European Dana Alliance for the Brain (EDAB), and its sister organisation in the United States, the Dana Alliance for Brain Initiatives. Every March, organisational partners throughout the world work to raise public awareness of the progress, promise and benefits of brain research. In 2004, over 1700 partners in 57 countries staged 661 events - reaching thousands of people, inspiring interest and providing information about the brain that everyone can understand.

The European Dana Alliance for the Brain functions as a catalyst for Brain Awareness Week, providing a framework in which any organisation, large or small, with expertise, can be involved. Organisations involved in Brain Awareness Week range from large national neuroscience organisations, to hospitals, to advocacy groups, to

Published online: 1 February 2005

\section{T. Davar (凶)}

Communications Officer,

European Dana Alliance for the Brain (EDAB),

The Dana Centre, 165 Queens Gate,

London SW7 5HE, UK

e-mail: enquiries@edab.net local primary schools. In addition, for the growing number of scientists (especially young scientists) who want to communicate their work to the public, Brain Awareness Week offers a convenient platform to do so.

Most organisations become involved by planning public events, and registering the events with the European Dana Alliance through its website. Other organisations involve themselves in different ways, including featuring special brain facts or messages about the brain in their newsletters and websites during Brain Awareness Week.

The European Dana Alliance also offers help to organisational partners in many different ways. The website offers resources on how to plan events, and graphics which partners can use on their materials. The Dana Alliance also offers free educational publications on the brain which organisers can hand out to audiences. In addition, all partner events are listed on a calendar on the website, which can be invaluable for other organisers to see.

The Dana Alliance encourages organisers to plan dynamic events which create a great deal of discussion, and which attract diverse audiences who normally would not have access. Often, when partner organisations develop educational events in countries or regions for the first time, they often make news headlines, and also generate tremendous public excitement.

Brain Awareness Week 2004 events included lectures and roundtable discussions on maintaining good health, anger management, obesity and new brain therapies, as well as concerts, dance productions, science cafes and laboratory open days, which attracted large audiences. Music, dance and science initiatives in the UK included a new dance choreography, Innervations, created by Southampton University, inspired by the science of brain cell communication. In London, the Institute of Neurology and the New London Orchestra, with 20 young secondary- 
school musicians, developed an experiment, Music on the Brain, to discover whether learning from sight or sound makes a difference to their performance. In Sweden, a jointly-funded project with a national bank enabled the Swedish Brain Foundation to translate Its Mindboggling, a leaflet for children produced by the Dana Alliance featuring information and games related to the brain, to be translated into Swedish, and distributed it to hundreds of schools to encourage students to pursue a career in neuroscience. In Lithuania, a non-government organisation dedicated to health education, and the Institute of Behavioural Neuroscience at Hangzhou Normal University in China, both organised comprehensive series of public lectures in difference cities, for various age groups, to promote health and lifestyle issues. Century City, the largest shopping mall in Cape province, South Africa, in conjunction with the Mental Health Information Centre (MHIC) of South Africa, designed and produced a three-minute educational video, screened at regular intervals in the Centre. Dereck Brumer, of Brain Injury Group, part of MHIC's extensive BAW programme committee, said "As vice-chairperson of BIG, I support the goal of this week $100 \%$ because there's a lot of ignorance about the undiscovered wonders of the brain. It's truly amazing that we keep discovering 'new' things that the brain is capable of...in that I include the healing powers of the brain... while we're only using a minimal portion of it."
The European Dana Alliance for the Brain (EDAB) is an alliance of more than 140 eminent brain scientists, including five Nobel laureates, from 27 countries. Launched in 1997 and born out of a similar organisation in the USA, EDAB is committed to promoting the importance of brain research. With offices in London and Lausanne, EDAB continues to work with partners worldwide to make information about the brain available to the public in an accessible and relevant way.

\section{How you can get involved}

You can bring brain research to life by running an event during the next Brain Awareness Week. By registering your event participation with $\mathrm{EDAB}$, you will receive information on running and publicising your programme, and will be listed in our online directory. You can also help spread brain information to the public in many other ways, including through your websites, newsletters, or e-mails.

For more information, see www.edab.net, contact EDAB on +44 (0)20 7019 4914, or e-mail enquiries@ edab.net. http://www.edab.net (English)

or http://www2.unil.ch/edab (French, German, and Italian) 